ISSN. 2775-4324 (Online)

Journal of Physical Activity and Sports (JPAS)

Volume 2, Nomor 1, April 2021, 122-129

Journal of Physical Activity and Sports

\title{
Analisis Teknik Lay Up dan Three Point Dalam Gerakan Shoot Bola Basket Tim Putra Kabupaten Sukamara Tahun 2020
}

\author{
Amy Thasia Pebriany ${ }^{1}$, Dian Ayu Zahraini ${ }^{2}$, Danang Aji Setyawan ${ }^{3}$ \\ Universitas PGRI Semarang. Jl. Sidodadi Timur No.24, 50232, Indonesia. \\ amythasia98@gmail.com 1, daz.charon@gmail.com 2, danangpjkrupgris@gamil.com 3
}

Received: 19-12-2020; Revised: 19-12-2020; Accepted: 29-04-2021

\begin{abstract}
This study aims to determine how the techniques and results of the lay-up and three-point analysis in the basketball shoot movement of the men's team in Sukamara Regency in 2020. This research uses a quantitative approach with descriptive analysis research type. The population and sample of the study were 12 athletes in the men's team of Sukamara Regency. The technique of collecting data is by taking video, the recordings are packed on DVD, and entered into the Dartfish Software. The results showed that the average score of all athletes in laying up very well was 11.4. Whereas for the three points the average distance of the eleven athletes is $11.12 \mathrm{~m}$, the jump height is 0.25 , the upper arm opening angle is $147.1^{\circ}$, the right hand angle is $165.1^{\circ}$, the body position is $172.0^{\circ}$, the right leg angle is $171.6^{\circ}$, the left leg angle is $173.0^{\circ}$, and $0.15 \mathrm{~m}$ foot openings. The conclusion of this research is that the implementation of the lay-up and three point test conducted by the twelve male team athletes of Sukamara Regency has done an average of very well. To be able to improve the lay-up and three-point movements, regular shooting practice is needed so that the more practice you will understand the position and accuracy in shooting.
\end{abstract}

Key words: Lay up analysis, three point

\begin{abstract}
Abstrak
Penelitian ini bertujuan untuk mengetahui bagaimana teknik dan hasil analisa lay up dan three point dalam gerakan shoot bola basket tim putra Kabupaten Sukamara tahun 2020. Penelitian ini menggunakan pendekatan kuantitatif dengan jenis penelitian deskriptif analisis. Populasi dan sampel penelitian adalah 12 atlet tim putra Kabupaten Sukamara. Teknik pengambilan data dengan cara mengambil video, hasil rekaman di kemas dalam bentuk DVD, dan dimasukan ke dalam Software Dartfish. Hasil penelitian menunjukkan bahwa nilai rata-rata dari keseluruhan atlet dalam melakukan lay up dengan sangat baik adalah 11,4. Sedangkan untuk three point rata-rata jarak kesebelas atlet adalah $11.12 \mathrm{~m}$, tinggi lompatan 0.25 , sudut bukaan lengan atas $147.1^{\circ}$, sudut tangan kanan $165.1^{\circ}$, posisi badan $172.0^{\circ}$, sudut sudut kaki kanan $171.6^{\circ}$, sudut kaki kiri $173.0^{\circ}$, dan bukaan kaki $0.15 \mathrm{~m}$. Kesimpulan dalam penelitian ini adalah dalam pelaksanaan tes lay up dan three point yang dilakukan oleh duabelas atlet tim putra kabupaten sukamara rata-rata sudah melakukan dengan sangat baik. Untuk dapat meningkatkan gerakan lay up dan three point diperlukan latihan shoot yang rutin sehingga semakin banyak berlatih semakin paham posisi dan ketepatan dalam melakukan shoot.
\end{abstract}

Kata kunci : Analisis lay up, three point

\section{PENDAHULUAN}

Berdasarkan hasil observasi dari daerah yang saya teliti diketahui masih banyak atlet basket tim putra Kabupaten Sukamara dalam melakukan shooting masih banyak memiliki kekurangan. Dalam melakukan latihan games terlihat bahwa ketika pada saat melakukan shooting masih banyak yang tidak tepat sasaran dan bahkan ketika melakukan three point masih banyak yang tidak mengenai bibir ring. 
Pada saat melakukan games selama 1 quarter dapat dilihat bahwa satu orang atlet bisa melakukan shoot sebanyak kurang lebih 8 tembakan hanya 3 kali yang masuk, maka dari itu peneliti akan meneliti tentang analisis teknik lay up dan three point shoot dalam gerakan bola basket tim putra kabupaten sukamara guna mengetahui penyebab kegagalan atlet tim putra Kabupaten Sukamara dalam melakukan shooting serta untuk mengetahui bagaimana hasil dari gerakan teknik lay up dan three point dalam gerakan shoot bola basket.

Peneliti memilih untuk mengambil tembakan lay up dan three point shoot adalah karena ingin menetili gerakan pada atlet tim putra kabupaten sukamara dan mencari tau penyebab mengapa tim putra Kabupaten Sukamara masih banyak yang tidak bisa melakukan lay up dan three point. Untuk sementara ini yang aktif latihan hanya tim putra saja, maka dari itu peneliti akan terfokus pada tim putra yang terdiri dari berbagai usia kisaran 15-20 tahun. Untuk mengamati dan mempelajari gerakan lay up dan three point shoot, peneliti akan menganalisa teknik lay up dan three point shoot dalam gerakan shoot bola basket tim putra kabupaten sukamara tahun 2020.

\section{METODE}

Metode yang digunakan dalam penelitian ini adalah kuantitaif dengan menggunakan jenis penelitian deskriptif analisis. Menurut Sugiyono (2013:13) Metode penelitian kuantitatif dapat diartikan sebagai metode penelitian yang berdasarkan pada filsafat positivisme, digunakan untuk meneliti pada populasi atau sampel tertentu, teknik pengambilan sampel pada umumnya dilakukan secara random, pengumpulan data menggunakan instrument penelitian, analisis data bersifat kuantitatif/statistik dengan tujuan untuk menguji hipotesis yang telah ditetapkan. (Menurut Sugiyono (2013: 147), metode Deskriptif adalah metode yang digunakan untuk menganalisis data dengan cara mendeskripsikan atau menjelaskan dan menggambarkan data yang telah dikumpulkan. Penelitian ini hanya sebatas pendeskripsian yaitu menganalisis rekaman video latihan lay up dan three point shoot yang meliputi analisis gerakan tangan, kaki, lemparan, serta hasil tembakkan.

Populasi dalam penelitian ini adalah Tim Putra bola basket Kabupaten Sukamara. Pengambilan sampel dilakukan dengan teknik purposive (sengaja). Metode penentuan sampel dalam penelitian ini menggunakan metode sensus atau sampling jenuh, yaitu metode pengambilan sampel bila semua anggota populasi digunakan sebagai sampel (Sugiyono, 2010). Jadi sampel yang digunakan dalam penelitian ini adalah tim putra Kabupaten Sukamara sebanyak 12 orang yang berumur antara 15-20 tahun.

Pengambilan data dilakukan dengan cara tahap persiapan, pengambilan video, dan analisis data. Yang petama tahap persiapan yaitu mempersiapkan kondisi sampel penelitian baik fisik maupun mental dan mengecek kondisi kamera yang akan digunakan, apakah berfungsi dengan baik atau belum. Yang kedua tahap pengambilan video (merekam) yaitu kamera diletakkan tegak lurus dengan subjek penelitian dengan jarak yang disesuaikan. kamera yang digunakan berjumlah tiga kamera yakni kamera 
yang diletakkan tegak lurus dengan posisi awal shooting, hasil shooting, dan dibelakang penembak, dengan aba-aba mulai, subjek penelitian mulai melakukan lay up dan three point, dan subjek penelitian melakukan lemparan sebanyak 3 kali. Yang ketiga tahap analisis yaitu langkah-langkah untuk memasukkan data (video) sampai analisis dalam penelitian ini, yang mengacu pada kuantitatif data dengan menggunakan fasilitas analyzer pada aplikasi softwere dartfish. Caranya dengan memasukkan video rekaman kedalam leptop, memilih fasilitas analyzer pada softwere dartfish untuk menentukan teknik lay up dan three point pada gerakan shooting bola basket dengan gerakan perlahan (slow-motion) dan menghentikan pada tahap-tahap yang diinginkan, menyimpan masing-masing video dengan sebelumnya memberi nama file-nya, memasukkan hasil analisis kedalam table pengamatan dan mulai melakukan analisis.

\section{HASIL DAN PEMBAHASAN}

Hasil penelitian analisis teknik lay up dan three point dalam gerakan shoot boola basket tim putra kabupaten sukamara tahun 2020 dapat dilihat pada tabel dibawah ini.

Tabel 1. Hasil Observasi Instrument Lay Up

\begin{tabular}{cccccc}
\hline Nama & \multicolumn{3}{c}{ Skor Akhir } & Rata-Rata & Ket \\
\cline { 2 - 4 } & Percobaan 1 & Percobaan 2 & Percobaan 3 & & \\
\hline Juselias & 12 & 12 & 9 & 11 & Sangat baik \\
\hline Satrio & 12 & 12 & 12 & 12 & Sangat baik \\
\hline Dwi Putra & 12 & 12 & 12 & 12 & Sangat baik \\
\hline Beben & 13 & 12 & 13 & 12.6 & Sangat baik \\
\hline Febri & 13 & 12 & 12 & 12.3 & Sangat baik \\
\hline Derren & 12 & 12 & 11 & 11.6 & Sangat baik \\
\hline Udi & 12 & 12 & 12 & 12 & Sangat baik \\
\hline Lintang & 13 & 12 & 13 & 12.6 & Sangat baik \\
\hline Wendy & 12 & 12 & 12 & 12 & Sangat baik \\
\hline Afif & 11 & 11 & 11 & 11 & Sangat baik \\
\hline Ayeng & 9 & 6 & 6 & 7 & Cukup \\
\hline Samuel & 11 & 11 & 11 & 11 & Sangat baik \\
\hline
\end{tabular}

Berdasarkan tabel diatas, nilai rata-rata dari keseluruhan atlet dalam melakukan lay up adalah 11,4 sedangkan untuk nilai maksimum keseluruhan atlet adalah 12,6 dan nilai minimum adalah 7 . Setiap atlet yang melakukan lay up dalam tiga kali kesempatan diambil yang terbaik untuk diteliti sudut gerakannya, dan menghasilkan sudut yang berbeda beda, dari duabelas atlet hanya sebelas atlet yang dapat melakukan lay up dengan sangat baik, sehingga dari kesebelas atlet tersebut masing-masing memiliki sudut gerakan sebagai berikut : 
Tabel 2. Persiapan Lay Up

\begin{tabular}{|c|c|c|c|c|c|c|c|c|c|c|c|c|}
\hline Item & \multicolumn{11}{|c|}{ Nama Atlet } & Rata- \\
\hline $\begin{array}{c}\text { Sudut } \\
\left(^{\circ}\right)\end{array}$ & Juselias & Satrio & $\begin{array}{l}\text { Dwi } \\
\text { Putra }\end{array}$ & Beben & Febri & Derren & Udi & Lintang & Wendy & Afif & Samuel & rata \\
\hline STK & 179.0 & 167.0 & 170.3 & 153.8 & 122.7 & 149.6 & 77.5 & 164.2 & 60.8 & 76.3 & 119.7 & 131.0 \\
\hline STKR & 140.0 & 145.0 & 173.6 & 19.0 & 154.4 & 147.1 & 116.6 & 135.3 & 151.7 & 138.6 & 140.5 & 132.9 \\
\hline PB & 27.7 & 30.5 & 33.1 & 79.6 & 38.2 & 13.1 & 35.2 & 43.6 & 8.1 & 31.8 & 14.8 & 32.3 \\
\hline SKK & 174.7 & 159.7 & 176.0 & 141.7 & 132.0 & 149.2 & 14.1 & 151.4 & 137.2 & 128.0 & 119.6 & 134.9 \\
\hline SKKR & 192.8 & 167.8 & 152.0 & 147.3 & 121.6 & 157.4 & 154.3 & 150.9 & 143.1 & 130.2 & 153.6 & 151.9 \\
\hline BK (m) & 0.19 & 0.70 & 0.01 & 0.42 & 0.44 & 0.16 & 0.80 & 0.31 & 0.48 & 0.29 & 0.06 & 0.35 \\
\hline
\end{tabular}

Berdasarkan rekapitulasi data dari tes pengukuran persiapan lay up akan disajikan pada tabel diatas ini. Pengukuran yang dimaksud disini adalah fokus pada gerakan tubuh yang dilakukan oleh objek, yakni sudut tangan kanan, sudut tangan kiri, posisi badan, sudut kaki kanan, sudut kaki kiri, serta bukaan kaki. Adapula rata rata pada tiap aspek guna membantu dalam proses penyimpulan data yaitu : pertama rata-rata sudut tangan kanan dari sebelas atlet yang melakukan lay up dengan sangat baik adalah 131.0, kedua rata-rata sudut tangan kiri $132,9^{\circ}$, ketiga rata-rata posisi badan $32,3^{\circ}$, keempat rata-rata sudut kaki kanan $134,9^{\circ}$, kelima rata-rata sudut kaki kiri $151,9^{\circ}$, dan yang terakhir rata-rata bukaan kaki 0,35 m.

Tabel 3. gerakan pelaksanaan Lay $U p$

\begin{tabular}{|c|c|c|c|c|c|c|c|c|c|c|c|c|}
\hline \multirow{2}{*}{$\begin{array}{c}\text { Item } \\
\text { Sudut } \\
\left(^{\circ}\right)\end{array}$} & \multicolumn{11}{|c|}{ Nama Atlet } & \multirow{2}{*}{$\begin{array}{r}\text { Rata- } \\
\text { rata }\end{array}$} \\
\hline & Juselias & Satrio & $\begin{array}{l}\text { Dwi } \\
\text { putra }\end{array}$ & Beben & Febri & Derren & Udi & Lintang & Wendy & Afif & Samuel & \\
\hline SBLA & 118.9 & 136.6 & 145.1 & 105.0 & 130.2 & 92.5 & 112.2 & 134.0 & 114.1 & 110.0 & 117.2 & 119.6 \\
\hline STK & 152.9 & 135.1 & 161.2 & 134.4 & 158.7 & 146.6 & 138.7 & 175.6 & 142.0 & 154.1 & 146.4 & 149.6 \\
\hline SKB & 165.4 & 172.9 & 163.1 & 177.0 & 164.7 & 164.3 & 154.0 & 176.8 & 159.2 & 158.9 & 150.3 & 164.2 \\
\hline SKK & 164.8 & 155.5 & 137.4 & 151.5 & 155.4 & 166.9 & 131.9 & 175.3 & 154.8 & 155.9 & 132.3 & 152.9 \\
\hline SKR & 175.0 & 166.4 & 165.5 & 177.2 & 65.2 & 161.6 & 167.3 & 176.4 & 165.1 & 177.3 & 162.8 & 160.0 \\
\hline BK & 0.35 & 0.15 & 0.20 & 0.22 & 0.12 & 0.48 & 0.40 & 0.41 & 0.35 & 0.49 & 0.31 & 0.32 \\
\hline
\end{tabular}

Berdasarkan rekapitulasi data dari tes pengukuran pelaksanaan lay up akan disajikan pada tabel diatas ini. Pengukuran yang dimaksud disini adalah focus pada gerakan tubuh yang dilakukan oleh objek, yakni sudut bukaan lengan atas, sudut tangan kanan, sudut kecondongan tubuh, sudut kaki kanan, sudut kaki kiri, serta bukaan kaki. Adapula rata rata pada tiap aspek guna membantu dalam proses penyimpulan data yaitu : pertama rata-rata sudut bukaan lengan atas dari sebelas atlet yang melakukan lay up dengan sangat baik adalah 119.6, kedua rata-rata sudut tangan kanan 149.6, ketiga rata-rata sudut kecondongan badan $164.2^{\circ}$, keempat rata-rata sudut kaki kanan $152.9^{\circ}$, kelima rata-rata sudut kaki kiri $160.0^{\circ}$, dan yang terakhir rata-rata bukaan kaki $0.32 \mathrm{~m}$. 
Tabel 4. gerakan followthrough Lay Up

\begin{tabular}{|c|c|c|c|c|c|c|c|c|c|c|c|c|}
\hline \multirow{2}{*}{$\begin{array}{c}\text { Item } \\
\text { Sudut } \\
\left(^{\circ}\right)\end{array}$} & \multicolumn{11}{|c|}{ Nama Atlet } & \multirow{2}{*}{$\begin{array}{l}\text { Rata- } \\
\text { rata }\end{array}$} \\
\hline & Juselias & Satrio & $\begin{array}{l}\text { Dwi } \\
\text { putra }\end{array}$ & Beben & Febri & Derren & $\overline{\text { Udi }}$ & Lintang & Wendy & Afif & Samuel & \\
\hline STLA & 138.0 & 146.6 & 159.8 & 149.6 & 148.7 & 127.2 & 143.6 & 175.1 & 145.8 & 140.3 & 143.9 & 147.1 \\
\hline STK & 156.2 & 136.7 & 159.1 & 155.6 & 158.0 & 144.7 & 161.4 & 174.8 & 156.7 & 155.4 & 149.4 & 155.3 \\
\hline SKB & 165.3 & 176.8 & 173.8 & 175.2 & 173.6 & 172.7 & 175.9 & 175.3 & 169.2 & 176.3 & 178.3 & 173.9 \\
\hline SKK & 167.0 & 167.8 & 170.4 & 173.6 & 159.2 & 166.7 & 161.8 & 178.0 & 166.9 & 169.7 & 172.9 & 168.5 \\
\hline $\begin{array}{c}\text { SKK } \\
\text { R }\end{array}$ & 176.4 & 170.2 & 173.6 & 171.1 & 83.8 & 169.6 & 179.7 & 178.8 & 173.2 & 173.2 & 167.1 & 165.2 \\
\hline $\begin{array}{l}\text { BK } \\
\text { (m) }\end{array}$ & 0.27 & 0.09 & 0.98 & 0.23 & 0.73 & 0.08 & 0.21 & 0.49 & 0.19 & 0.13 & 0.51 & 0.36 \\
\hline
\end{tabular}

Berdsarkan rekapitulasi data dari tes pengukuran followthrough lay up akan disajikan pada tabel diatas ini. Pengukuran yang dimaksud disini adalah focus pada gerakan tubuh yang dilakukan oleh objek, yakni sudut tekukan lengan atas, sudut tangan kanan, sudut kecondongan tubuh, sudut kaki kanan, sudut kaki kiri, serta bukaan kaki. Adapula rata rata pada tiap aspek guna membantu dalam proses penyimpulan data yaitu : pertama rata-rata sudut tekukan lengan atas dari sebelas atlet yang melakukan lay up dengan sangat baik adalah $147.1^{\circ}$, kedua rata-rata sudut tangan kanan $155.3^{\circ}$, ketiga rata-rata sudut kecondongan badan $173.9^{\circ}$, keempat rata-rata sudut kaki kanan 168.5, kelima rata-rata sudut kaki kiri $165.2^{\circ}$, dan yang terakhir rata-rata bukaan kaki $0.36 \mathrm{~m}$.

Tabel 5 hasil observasi Instrument Three Point

\begin{tabular}{cccc}
\hline No & Rentang skor & Kriteria skor & Jumlah atlet \\
\hline $\mathbf{1}$ & $0-2$ & Kurang sekali & 0 \\
$\mathbf{2}$ & $3-5$ & Kurang & 0 \\
$\mathbf{3}$ & $6-8$ & Cukup & 0 \\
$\mathbf{4}$ & $9-11$ & Baik & 1 Orang \\
$\mathbf{5}$ & $12-15$ & Baik sekali & 11 Orang \\
\hline
\end{tabular}

Berdasarkan hasil penelitian yang sudah dilaksanakan dan mendapatkan hasil penelitian dari 3 kali kesempatan dalam melakukan three point shoot didapatkan hasil sebagai berikut :

$$
\begin{aligned}
& \frac{1}{12} \times 100 \%=8,3 \% \text { kategori Baik } \\
& \frac{11}{12} \times 100 \%=91,6 \% \text { kategori Sangat Baik }
\end{aligned}
$$

Berdasarkan tabel diatas dalam 12 atlet yang sudah melakukan tes three point didapatkan hasil 11 atlet yang melakukan tes three point dengan sangat baik. Dan satu orang melakukan tes three point 
dengan baik dan menghasilkan sudut yang berbeda beda, sehingga dari kesebelas atlet tersebut masingmasing memiliki sudut gerakan sebagai berikut :

Tabel 6. rata-rata hasil three point

\begin{tabular}{|c|c|c|c|c|c|c|c|c|c|c|c|c|}
\hline \multirow{2}{*}{$\begin{array}{l}\text { Sudut } \\
\text { Item } \\
\left(^{\circ}\right)\end{array}$} & \multicolumn{11}{|c|}{ Nama Atlet } & \multirow[t]{2}{*}{ Rata-Rata } \\
\hline & Juselias & Satrio & $\begin{array}{l}\text { Dwi } \\
\text { putra }\end{array}$ & Beben & Febri & Derren & Udi & Lintang & Wendy & Afif & Samuel & \\
\hline $\begin{array}{c}\text { JRK } \\
(\mathbf{m})\end{array}$ & 8.79 & 8.12 & 8.55 & 9.13 & 14.1 & 12.58 & 11.35 & 11.83 & 11.8 & 12.68 & 13.35 & 11.12 \\
\hline $\begin{array}{l}\text { TL } \\
\text { (m) }\end{array}$ & 0.23 & 0.14 & 0.22 & 0.15 & 0.48 & 0.24 & 0.46 & 0.21 & 0.33 & 0.13 & 0.19 & 0.25 \\
\hline SBL & 139.2 & 145.1 & 152 & 155 & 145.1 & 140.1 & 144.6 & 143.4 & 164.5 & 149.5 & 140.3 & 147.16 \\
\hline STK & 139.9 & 177.5 & 176.6 & 163.4 & 167.9 & 169.6 & 156 & 160.1 & 160.7 & 167.5 & 177.5 & 165.15 \\
\hline PB & 171.8 & 161.1 & 178.1 & 176.1 & 176.1 & 170.3 & 174.6 & 179.8 & 173.4 & 164.9 & 166.1 & 172.03 \\
\hline SKN & 174.4 & 174.7 & 170.9 & 175.6 & 176.6 & 155.2 & 170.9 & 175.8 & 172.6 & 165.3 & 175.7 & 171.61 \\
\hline SKR & 176.6 & 175.1 & 175.2 & 173.1 & 175.1 & 179.5 & 172.7 & 167.4 & 174.6 & 161.7 & 172 & 173.00 \\
\hline $\begin{array}{l}\text { BK } \\
(\mathbf{m})\end{array}$ & 0.25 & 0.13 & 0.24 & 0.17 & 0.26 & 0.01 & 0.12 & 0.16 & 0.16 & 0.12 & 0.08 & 0.15 \\
\hline
\end{tabular}

Rekapitulasi data dari tes pelaksanaan three point hasil yang didapatkan oleh kesebelas atlet yang melakukan dengan sangat baik akan disajikan pada tabel diatas ini. Pengukuran yang dimaksud disini adalah focus pada gerakan tubuh yang dilakukan oleh objek, yakni jarak atlet yang melakukan three point pada ring basket, sudut bukaan lengan atas, sudut tangan kanan, sudut posisi badan, sudut kaki kanan, sudut kaki kiri, serta bukaan kaki. Adapula rata rata pada tiap aspek guna membantu dalam proses penyimpulan data yaitu : pertama rata-rata jarak yang dilakukan kesebelas atlet ke ring basket adalah 11.12, kedua rata-rata tinggi lompatan keseblas atlet adalah 0.25 , ketiga rata-rata sudut bukaan lengan atas adalah $147.1^{\circ}$, keempat rata-rata sudut tangan kanan $165.1^{\circ}$, kelima rata -rata sudut posisi badan $172.0^{\circ}$, keenam rata-rata sudut sudut kaki kanan 171,6, ketujuh rata-rata sudut kaki kiri 173,0 , dan yang terakhir rata-rata bukaan kaki $0.15 \mathrm{~m}$.

\section{KESIMPULAN}

Berdasarkan hasil dan penelitian dapat disimpulkan bahwa :

1. Dalam pelaksanaan tes lay up yang dilakukan oleh duabelas atlet tim putra kabupaten sukamara rata-rata sudah melakukan dengan sangat baik. Hasil nilai rata-rata dari keseluruhan atlet dalam melakukan lay up adalah 11,4 sedangkan untuk nilai maksimum keseluruhan atlet adalah 12,6 dan nilai minimum adalah 7 .

2. Dalam pelaksanaan tes three point yang dilakukan oleh dua belas atlet tim putra kabupaten sukamara rata-rata sudah melakukan dengan sangat baik. Hasil pelaksanaan tes three point adalah rata-rata jarak yang dilakukan atlet ke ring basket adalah 11.12, rata-rata tinggi lompatan adalah 0.25 , rata-rata sudut bukaan lengan atas adalah $147.1^{\circ}$, rata-rata sudut tangan kanan $165.1^{\circ}$, rata -rata 
sudut posisi badan $172.0^{\circ}$, rata-rata sudut sudut kaki kanan 171,6, rata-rata sudut kaki kiri 173,0 , dan rata-rata bukaan kaki $0.15 \mathrm{~m}$.

\section{DAFTAR PUSTAKA}

Agung Indra Permana, R. (2016). PENINGKATAN HASIL BELAJAR LAY UP SHOOT DALAM PEMBELAJARAN BOLABASKET DENGAN PRMAINAN LOMPAT KIJANG PADA PESERTA DIDIK KELAS VIII C SMP NEGERI GALUR TAHUN AJARAN 2015/2016. Jurnal Pendidikan, Jasmani Indonesia, 1-4.

Anggara Budi P. 2016. TINGKAT KEMAMPUAN LAY UP SHOOT PADA SISWA YANG MENGIKUTI EKSTRAKURIKULER BOLABASKET DI SMK LEONARDO KLATEN. Skripsi.

Ardian Khoerul Anal, T. H. (2014). ANALISIS GERAK TENDANGAN DEPAN PADA EKSTRAKULIKULER PENCAK SILAT. Journal of Sport Sciences and Fitness, 19-24.

Arifin, B. (2014). ANALISIS GERAK TRACSTAR UNTUK MEMAKSIMALKAN JARAK LOMPATAN START PADA RENANG DITINJAU DARI KAJIAN BIOMEKANIKA (Studi pada atlet renang SC Eagle Surabaya). Sains Olahraga : Jurnal Ilmiah Keolahrgaan , 105-111.

Fachru Falah Adina, S. R. (2018). ANALISIS GERAK JUMP SHOOT TERHADAP TINGKAT KEBERHASILAN POINT DI TIM BOLA BASKET UNIT KEGIATAN MAHASISWA.

Gietra, Rige 2017. ANALISI KETERAMPILAN SHOOTING FREE TROW PADA SISWA PESERTA EKRAKURIKULER SMPN 1. Kota Bengkulu (skripsi). Bengkulu Universitas Bengkulu

Ibeng, P. (2020, Maret 24). Pengertian Olahraga, Tujuan, Manfaat, Jenis, dan Menurut Ahli. Retrieved from Pengertian Olahraga, Tujuan, Manfaat, Jenis, dan Menurut Ahli: pendidikan.co.id/pengertian-olahraga-tujuan-manfaat-jenis-dan-menurut-ahli/

Kurniawan, F. F. (2019). PERBANDINGAN EFEKTIVITAS MEDIUM SHOOT DENGAN LONCATAN DAN TANPA LONCATAN TERHADAP AKURASI HASIL SHOOTING. Sains Olahraga : jurnal Ilmiah Ilmu Keolahragaan, 99-107.

Maksum, Ali. 2012. METODOLOGI PENELITIAN DALAM OLAHRAGA. Surabaya: Unesa University Press-2012.

Perbasi, 2010. TERJEMAHAN PERATURAN PERMAINAN BOLA BASKET. Jakarta: PB Perbasi

Raden Arfin Kusuma Winata, M. Y. (2019). ANALISIS GERAK THREE POINT SHOOT (STUDI KOMPERASI PADA PEMAIN BASKET KYRIE IRVING DENGAN SANDY KURNIAWAN).

Sugiyono. 2011. METODE PENELITIAN PENDIDIKAN KUANTITATIF, KUALITATIF DAN R\&D, Bandung : Alfabeta.

Sugiyono. 2013. METODE PENELITIAN PENDIDIKAN KUANTITATIF, KUALITATIF DAN R\&D, Bandung : Alfabeta.

SUWADJI, A. S. (2014). ANALISIS GERAK LEMPAR LEMBING (Studi Pada Atlet Cabor Lempar Lembing PASI Sidoarjo, Ditinjau dari Aspek Biomekanika dan Kinesiologi). Sains Olahraga: Jurnal Ilmiah Ilmu Keolahragaan, 73-82. 
Analisis Teknik Lay Up dan Three Point Dalam Gerakan Shoot Bola Basket

Tim Putra Kabupaten Sukamara Tahun 2020

Amy Thasia Pebriany ${ }^{1}$, Dian Ayu Zahraini ${ }^{2}$, Danang Aji Setyawan ${ }^{3}$

Widiastuti. (2011). TES DAN PENGUKURAN OLAHRAGA. Jakarta: PT Bumi Timur Jaya.

Disampaikan dalam skripsi Muhammad Nafis Muzakki, 23 April 2019. 